Original Article

\title{
FOOT DEFORMATIONS IN COCONUT TREE CLIMBERS OF SOUTH INDIA
}

\author{
Bincy M. George ${ }^{1}$, Arunachalam Kumar ${ }^{2} \&$ Muddanna S.Rao ${ }^{3}$ \\ ${ }^{1}$ Assistant Professor, Department of Anatomy, M elaka M anipal M edical College (M anipal Campus), Manipal University, \\ Udupi, Karnataka, India., ${ }^{2}$ Professor \& Head, Department of Anatomy, K. S. Hegde M edical Academy, Nitte University, \\ Mangalore - 575 018, India., ${ }^{3}$ Associate Professor in Anatomy, Faculty of Medicine, Kuwait University, Safat, Kuwait. \\ Correspondence: \\ Bincy M. George \\ Phone: +91 820 2922519. M obile +91 99861 04682. Fax : t91 8202571905 E-mail : bincyrajakumary@yahoo.com
}

\begin{abstract}
:
There are observable foot changes in professional coconut tree climbers of south India, but those are not reported in literature. Objective of the present study was to quantify the foot adaptations in south Indian coconut tree climbers.

Data from a total of 220 male volunteers, between $18-55$ years of age, engaged in the profession of coconut tree climbing were collected to find the anatomical changes in foot in them.

The data revealed the coconut tree climbers are having prominent pes cavus, varus foot and abducted great toe. The adaptation pattern of foot varies depending upon the pressure it is subjected to bear.

This study establishes an occupationally induced form of foot deformations or adaptations which are not, reported much in the literature.
\end{abstract}

Keywords: Coconut tree climbers, Occupational adaptations, Foot

\section{Introduction:}

Evolution of a functional bipedal gait has been the hallmark in the transition dynamics that project man from the pithecoides era ${ }^{(1)}$. The change in the usage or function of foot from arboreal existence to terrestrial living has been responsible for the anatomical changes seen in more distal segments of the upper and lower limbs ${ }^{(2,3)}$

The human foot is designed to bear weight and aid bipedal locomotion ${ }^{(4)}$. The ligaments, joints, bones, muscles and soft tissue components of the foot contribute in its own unique manner in making man alone among his mammalian cousins, to have mastered the art of walking on hind $\operatorname{limbs}^{(5)}$. Combined effect of hereditary and acquired life style, such as Access this article online Quick Response Code

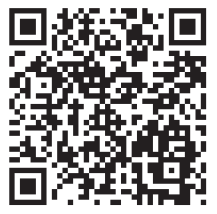
occupation play a significant role in shaping foot morphometrics ${ }^{(6,7)}$. It is interesting to note that the foot morphology does undergo tremendous morphological changes in its transition from arboreal to terrestrial form ${ }^{(8)}$.

In coastal south India, traditionally trained people, mostly belonging to the special communities, climb trees, particularly coconut trees. The tree climbers use their hands and legs to climb the tree. When they climb, the legs are flexed on each side of the tree with the soles of the feet applied around the tree trunk. (Usually they use a loop of coir at the ankle for support, Fig.1). Hands encircle the tree trunk. A few of them use coir loop between the hands to grab the tree trunk. By gripping the tree with extended upper limbs, they lift the body upwards. During this process of tree climbing hip joint makes flexion, extension, abduction and lateral rotation, knee joint undergoes flexion and extension and inversion at the subtalar joints, along with the flexion of toes. The climbers carry a sickle or special type of knife with hood at their holster or collar. When they reach the top the tree, they hold one of the coconut tree leaves, with one hand and pull out the coconuts with the knife in other hand. The whole process of climbing and plucking coconut take 8-10 minutes, wherein they use 1 to 2 minutes to climb and 30 seconds to 
1 minute to climb down. A healthy coconut tree climber starts his work very early in the morning $(5.30-6.00$ hrs.)and end the work by 11.00 hrs., as the sun rays does not suit for vertical ascend after that time. During this period they can harvest 20-30 trees, depending on the proximity of the trees. They usually work seven days a week. Gripping the tree trunk with fully inverted feet, which bears the climbers body weight, demands tremendous stress and strain at the osteoarchitecture of the foot. Climbing large diameter trees like coconut tree require higher costs of locomotion ${ }^{(6)}$.

Osteoarchitectural adaptations of foot in professional dancers, and athletes have been studied ${ }^{(9)}$. Foot ankle injuries in occupational medicine are also studied ${ }^{(10)}$. But we hardly find any reference to occupation induced adaptation or change of foot in tree climbing professionals. The study is of importance in this circumstance as we may uncover the causative factors of the main occupational deformations in this particular agricultural industry and recommend measures to avoid them. It has been observed that a number of grievous injuries and fatalities occurred due to accidental fall from trees according to local daily news reports. It is intriguing that most of these casualties occur in the more experienced and older tree climbers in the community

Occupation based permanent change and adaptations to the foot due to pressure, and fall from tree have attracted far less attention. The present study was aimed to study the morphological and functional changes and adaptation of foot to the stress and strain demanded by tree climbing occupation.

\section{Objective :}

To record the observable changes in the foot anatomy of professional coconut tree climbers in south India.

\section{Subjectsand methods:}

The data presented in this paper were obtained from an observational study conducted on professional coconut tree climbers between January 2006 and December 2008. A total of 220 volunteers aged less than 55 years from the few villages of Kerala (Kozhikode, Ernakulam, Kollam, Idukki districts) and Tamilnadu (Body, Bodynayakannur districts) states. All the subjects were regular professional tree climbers who climb large diameter $(450-600 \mathrm{~mm})$ coconut trees without using any external climbing aids.

\section{Study Design}

\section{a. Field survey}

Field observations of the coconut plantation industry were made to note the type and circumference of the coconut tree and the techniques of tree climbing used by tree climbing professionals. Visually identifiable gross changes and adaptations of the feet were tabulated from volunteered coconut tree climbers who have been not subjected to any hospital based investigations or invasive procedures. Feet of coconut tree climbers that mimic certain deformations were photographed.

\section{b. First ray examination:}

For first ray position examination, the position of the head of the first metatarsal bone of both feet, were observed, palpated and compared to the heads of other metatarsals. The plantar and dorsal aspect of the first metatarsal head was grasped between the thumb and index finger of one hand. The lateral 4 metatarsal heads were grasped between the thumb and digits of the opposite hand. Gentle pressure was applied to compress the plantar fat pads to palpate the metatarsal heads. If the first metatarsal head was found in the same plane as the remaining four, it was graded as normal. If the first metatarsal head was found higher than the remaining metatarsals, it was graded as dorsiflexed. If the first metatarsal head was found below the remaining metatarsals, it was graded as plantar flexed (11-13).

\section{Results:}

\section{a. Observations on foot deformities}

Complex movements of foot which were used by climbers while ascending and descending are plantarflexion and dorsiflexion at ankle joint, inversion at subtalar joint, flexion of metatarsophalangeal and interphalangeal joints. The climbing induces tremendous strain on the ankle, subtalar and intertarsal joint. The large areas of the tree 


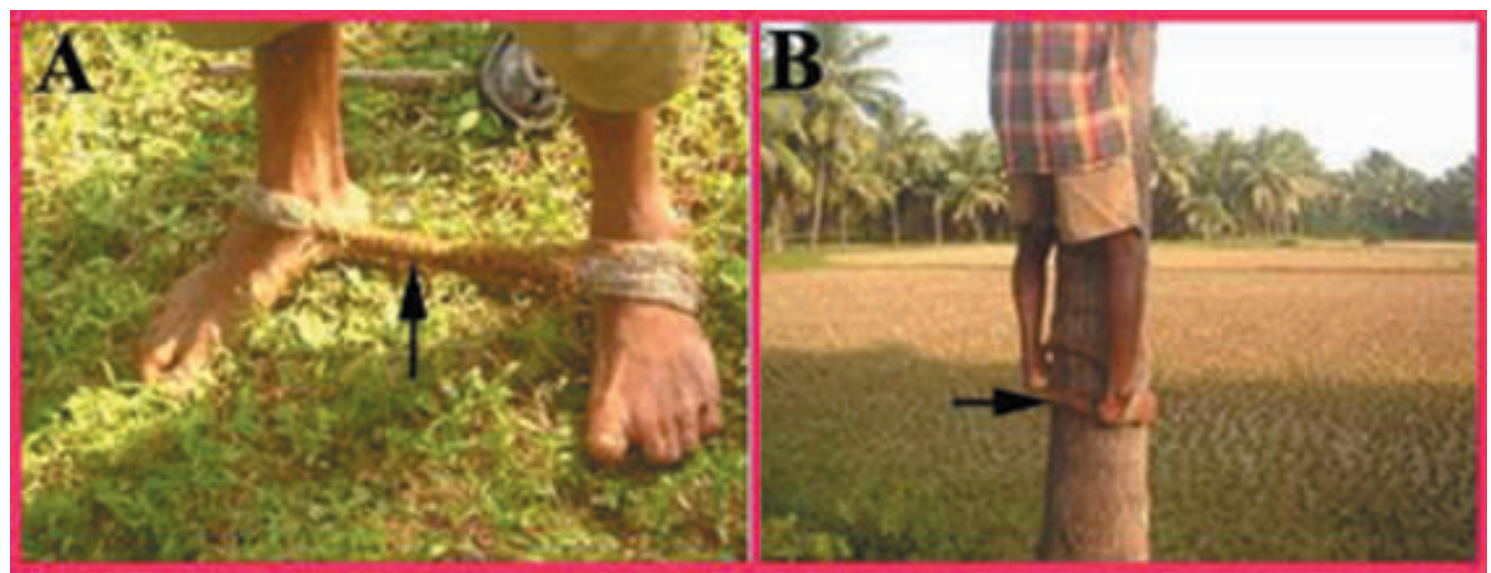

Figure 1: A. a rope belt or ankle belt (arrow) used by the coconut tree climbers (A),B. Climber climbing the coconut tree by gripping the tree trunk with the ankle belt ( arrow).

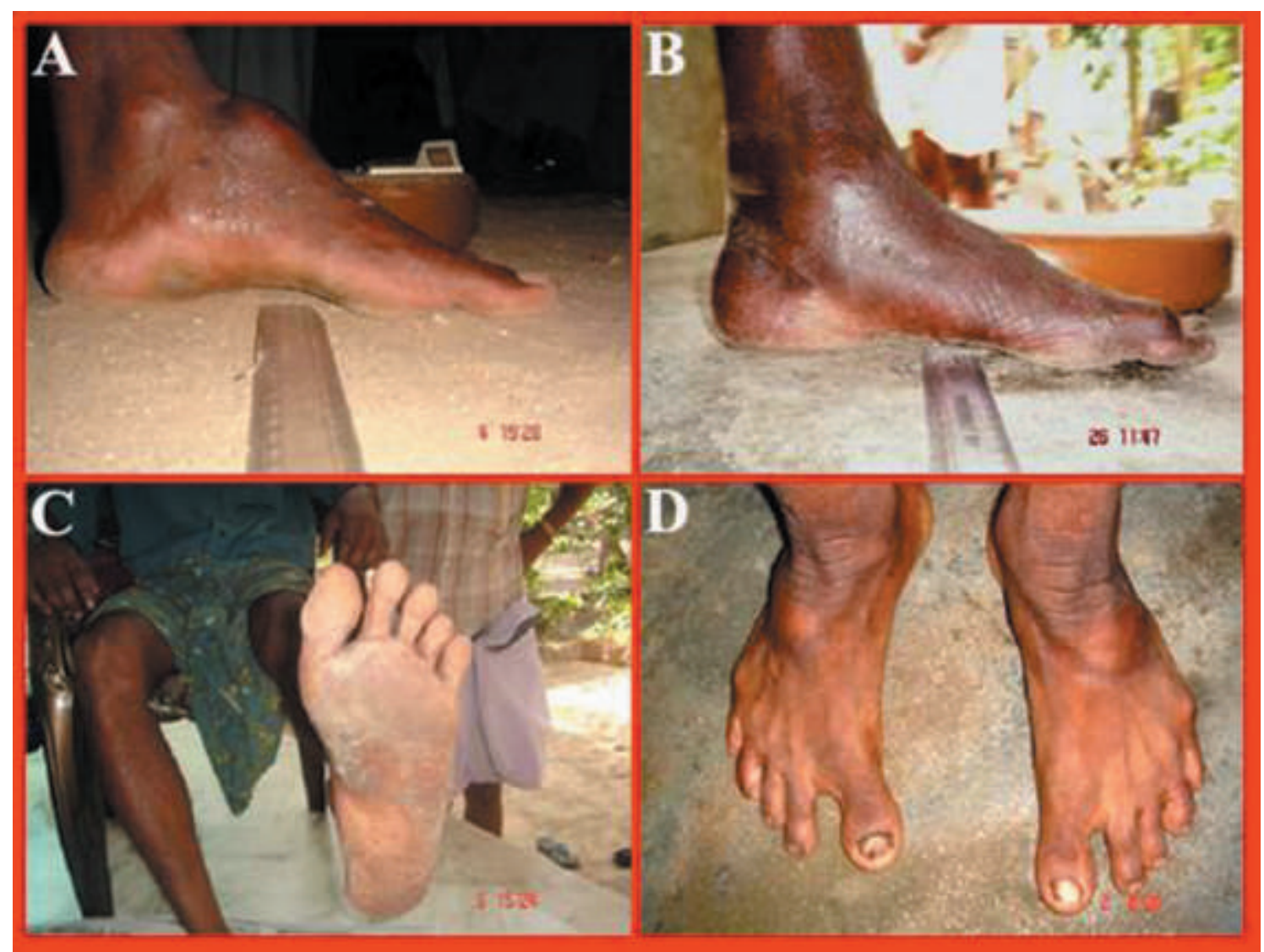

Figure 2: Foot modifications in different individuals having the coconut tree climbing as their occupation. A-M edial aspect of the foot with plantar flexed first ray, B-M edial aspect foot with hallux hammer toe, C-Plantar aspect of the foot with halluxvalgus, D -Dorsal aspect of the feet with varus forefoot, abducted halluxand medially deviated toes.

trunk, along with the loop worn at the ankles, give a lateral thrust at the metatarsophalangeal joints. In the coconut tree climbers we observed the following deformities in the foot. (i) Plantar flexed first ray(Fig.2A),(ii) Abducted hallux, (iii) Hammer toe(Fig.2B), (iv) Hallux valgus and laterally deviated toe (Fig.2C), (v) Varus foot with medially deviated toe(Fig.2D),(vi)Cavus foot(Fig.3A),(vii) Varus hind foot(Fig.3C,D). We have also found callous formation in the plantar aspect of foot in coconut tree climbers having more than ten years of experience 


\section{b. Qualitative data on deformities}

The percentage incidences of the deformities in left and right feet in coconut tree climbers are shown in table-1.

\section{Discussion :}

The kinematics of the first ray plays a key role in medial longitudal arch during gait $\left.{ }^{(14)}\right)$. The first ray is a critical element in controlling the structural integrity of the foot. Faulty mechanics of the first ray can contribute to foot pathology ${ }^{(15)}$. First ray can be classified as rigid plantar flexed when the first metatarsal is plantar flexed in a fixed position relative to the other metatarsals. In normal gait, the plantarflexed first ray restricts the internal rotation of the tibia in stance phase which in turn results in inability of calcaneous to evert and therefore the shock absorbtion of

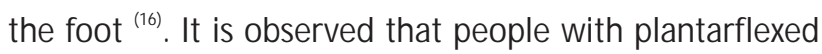
first rays have callus formation beneath the head of first metatarsal bone as well as the great toe ${ }^{(17)}$. We have found the similar type of callous formation in coconut tree climbers having more than ten years of experience. This suggests that sheer and compressive forces acting on the first metatarsal may be abnormally high during stance phase of the tree ascend. Thus the callus formation provides evidence that rigid plantarflexed first ray compromises the ability of the medial arch to attenuate the shock of impact during weight acceptance ${ }^{(18,19)}$.

In the present study we found that $26.4 \%$ (right foot) and $18.2 \%$ (left foot) of rigid plantarflexed first ray. This suggests the strong adaptation of medial longitudinal arch with their occupation. The callus formation found on the plantar aspect of first metatarsal head and hallux gives strong evidence that the ability of the medial longitudinal arch to absorb shockis questionable.

Disturbances of fingers and toes are reported in isolated cases; where they were found to be deviated from the normal pattern ${ }^{(20)}$. Laterally deviated great toe or hallux valgus is one of the common disorders of the foot. Laterally deviated toe is commonly associated with a deformity of the first metacarpophalangeal joint ${ }^{(21,22)}$. The complex relationship of the first ray biomechanics and hind foot mechanics influence bunion development. Bunion can be secondary to any structural adaptation and over the time may lead to callus formation ${ }^{(22-25)}$. Biomechanics of laterally deviated toe exerts pressure on first metatarsal to deviate medially. Thus hallux valgus is usually associated with medial deviation of first metatarsal resulting in a forefoot disorder rather than deformation restricted to great toe ${ }^{(7)}$.The evidence shows that the most common cause of hallux valgus in adults starts with lateral deviation of the hallux from external forces such as shoe wear ${ }^{(7,26)}$. Incidence of hallux valgus varies in literature .On an average $16-33 \%$ of the male population of shoe wearing races is said to be affected by hallux valgus ${ }^{(25,27)}$.

As the present set up is the non-shoe wearing, socio economically backward community of a developing country, it may not be feasible to compare the data with the reported ones. We noticed less than $6 \%$ of the people in the coconut tree climbing communities and $1 \%$ of nonclimbers had observationally prominent hallux valgus. Varus force applied to the first metatarsal while climbing trees might be acting as a compensatory biomechanics of the first metatarsophalangeal joint to subluxate and produce valgus of the great toe (Hypothesis supported by the literature ${ }^{228.31}$. It is interesting to note that $23.18 \%$ of the coconut climbers presented with laterally deviated (2nd to $\left.5^{\text {th }}\right)$ toes, while none of the non climbers showed such pattern in their toes. The external force induced by the tree ascend towards lateral direction of toe together with spreading pressure on lateral toes to grip the tree may be the reason for it.

Underlying toes and overlapping toes are reported as congenital foot anomalies ${ }^{(32)}$. Congenital over riding of the little toe alone is also reported ${ }^{(32,33)}$. But there is no report of overlapping of adult toes due to external pressure. The increase in percentage of overlapping of toes in coconut climbers (5 to $5.45 \%$ ) compared to non climbers $(0.45 \%)$ suggests the probable incidence of a new variety of occupation induced overlapping of toes.

Data regarding complications or impairment due to hindfoot varus is lacking in literature. This may be because goniometric and visual clinical assessment of rear foot is 


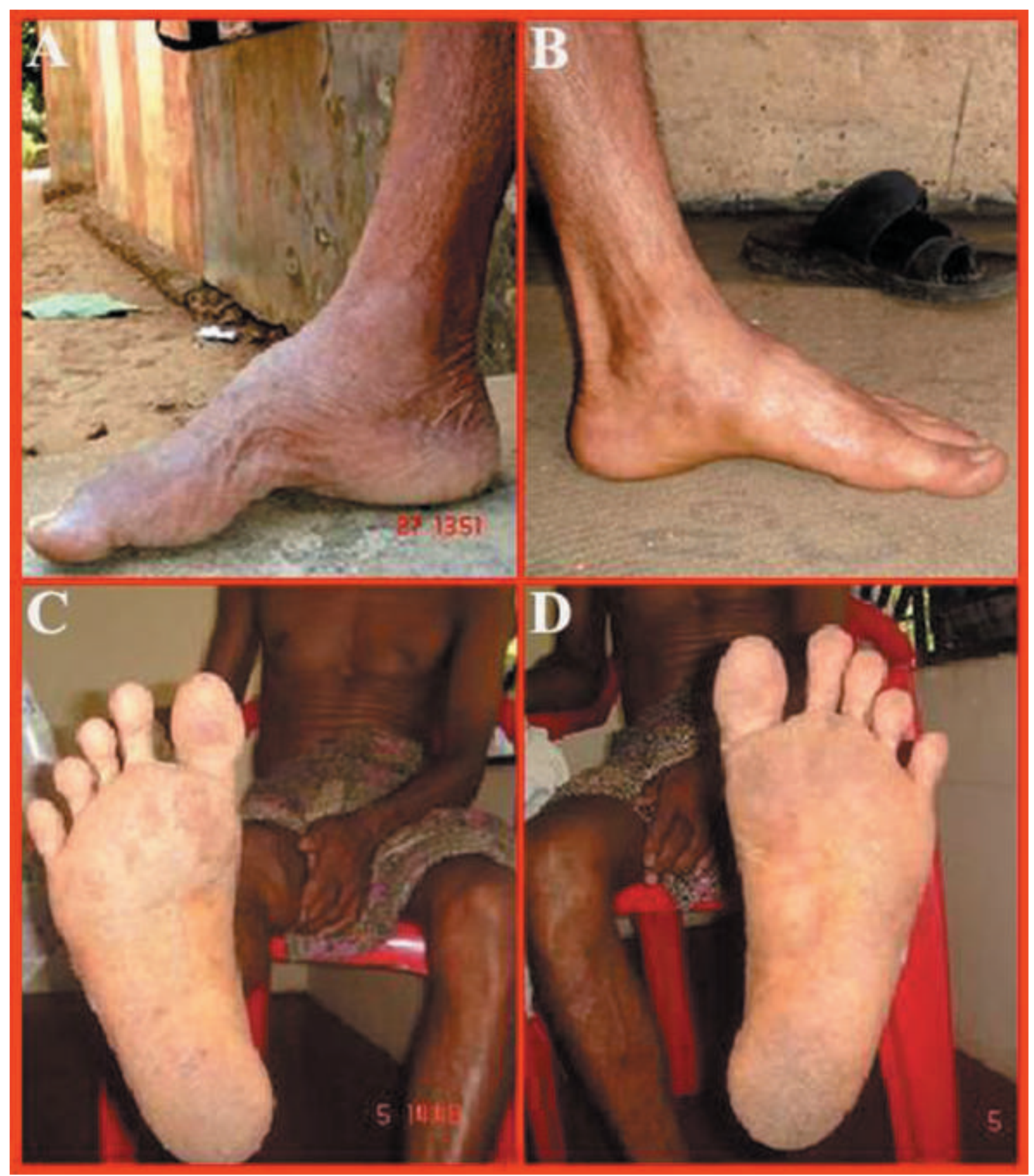

Figure 3: Foot of coconut tree climber's and non climbers. A-Cavus foot in a coconut tree climber, B- a non climber's foot. C and D -Climber's feet showing bilateral hind foot varus.

\begin{tabular}{|l|c|c|c|c|c|c|c|c|c|c|}
\hline \multicolumn{10}{|c|}{ Foot deformations (\%) } \\
\hline & VFF & DFR & HT & MDT & OT & HV & VHF & LDT & PFR & CF \\
\hline Right foot & 0.90 & 1.40 & 1.80 & 1.80 & 5.00 & 5.90 & 6.36 & 23.18 & 26.40 & 69.00 \\
\hline Left foot & 0.90 & 0.45 & 0.90 & 1.36 & 5.45 & 4.54 & 5.90 & 23.18 & 18.20 & 63.00 \\
\hline
\end{tabular}

Table.1: Frequency(\%) of different types of observable foot deformations found in coconut tree climbers. VFF-Varus Fore Foot, DFR-Dorsiflexed First Ray, HT-Hammer Toe, MDTM edially Deviated Toes. OT-Over-laping Toes. HV-Hallux Valgus. VHF-Varus Hind Foot. LDTLaterally Deviated Toes. PFR-Plantarflexed First Ray, CF-Cavus Foot. 
considered as unreliable ${ }^{(32)}$. M any suggest the radiographic analysis of the rear foot is the best way of analyzing its deformities or deviation ${ }^{(34-38)}$. In the present study we have not done procedure such as radiography. But the observational hind foot varus seen in $6.39 \%$ (Table- 1 ) people draws attention for future studies using radiography. Small percentage (1.8\%, Table- 1$)$ of people with medially deviated toes (Fig.2D.), and hammer toes (Fig.2B) raises the question, whether they need to be considered as adaptations due to subjective change of usage of foot in climbing.

\section{Conclusion:}

Hallux valgus, laterally deviated toes, callosities over the

\section{References:}

1. Isler K.3D-kinematics of vertical climbing in hominoids. Am J Phys Anthropol. (2005)126(1):66-81.

2. Preuschoft $\mathrm{H}$. M echanisms for the acquisition of habitual bipedality: are there biomechanical reasons for the acquisition of upright bipedal posture? J. Anat. (2004)204, pp363-384

3. Preuschoft H. What does "arboreal locomotion" mean exactly and what are the relationships between "climbing", environment and morphology? ZM orphol Anthropol. (2002) 83(2-3):171-88.

4. Watson JC, Payne RC, Chamberlain AT, Jones RK, Sellers WI. The energetic costs of load-carrying and the evolution of bipedalism. J Hum Evol.(2008) M ay;54(5):675-83.

5. Bender R, Verhaegen M, Oser N. Acquisition of human bipedal gait from the viewpoint of the aquatic ape theory Anthropol Anz. (1997)55(1):1-14.

6. Isler K. Footfall patterns, stride length and speed of vertical climbing in spider monkeys (Ateles fusciceps robustus) and woolly monkeys (Lagothrix lagotricha). Folia Primatol (Basel). (2004)75(3):133-49. Aminian A, Bruce J. Sangeorzan .The Anatomy of Cavus Foot Deformity foot and ankle clinics. (2008) 13(2): 191-198.

7. Hart ES; deasla RJ; Grottkau B E.Current Concepts in the Treatment of Hallux Valgus Orthopaedic Nursing (2008) 27, 5; ProQuest Medical Library. 274 .

8. Harcourt-Smith WE, Aiello LC. Fossils, feet and the evolution of human bipedal locomotion. J Anat. (2004)204(5):403-16.

9. Sammarto GJ. The foot and ankle in dancers In: Helal B, Wilson D. The foot: volume 2; Churchill Livingstone.(1988) 49; 994- 1033

10. Grimm DJ, Fallat L. Injuries of the foot and ankle in occupational medicine: a 1-year study.J Foot Ankle Surg. 1999 M ar-Apr;38(2):102-8.

11. Donatelli R, Wolf SL. The Biomechanics of the Foot and Ankle. Philadelphia, PA: FA Davis(1990)23-26,141-142.

12. Glasoe WM, Yack HJ, Saltzman CL. Anatomy and biomechanics of the first ray. Phys Ther. (1999)79:854-859.

13. Shirk C, Sandrey MA, Erickson M. Reliability of first ray position and mobility measurements in experienced and inexperienced examiners. J Athl Train. (2006) 41(1):93-9; discussion 99-101.

14. Morton DJ. Structural factors in static disorders of the foot. Am J Surg.(1930) 9:315-326.

15. Campbell J T. Preface. Foot and Ankle, Clinics. M arch (2009)14(1), xi-xil

16. Hamill J, Bates BT, Knutzen KM , Kirkpatrick GM . Relationship between selected static and dynamic lower extremity measures. Clin Biomech. (1989)4:217-225.

17. Michaud, T.M .Foot Orthoses and Other Forms of Conservative Foot Care, Williams and Wilkins, Baltimore. (1993)64-65, 186 first metatarsal joint area, varus hind foot and overlapping of the toes were the major observational changes found in foot of coconut climbers apart from the prominent cavus foot in most of them. None of the deformations were associated with pain at the time of survey. We hope this study add more information to the field of occupational medicine, to highlight the occupationally induced foot adaptations/ deformation. This information bought by this study may help for further study on the impact of deformation in coconut tree climber's occupational habitat, their gait analysis and thus improve their health status by re-educating or rehabilitating them.

18. Humbert J L, Bourbonnire C; Laurin CA, M etatarsophalangeal fusion for hallux valgus: Indications and effect on the first metatarsal ray CM A journal (1979) 120,;937-956.

19. Glasoe WM , Allen M K, Yack HJ. M easurement of dorsal mobility in the first ray: elimination of fat pad compression as a variable. Foot Ankle Int. (1998)19:542-546.

20. Hiscox E J, Trophic disturbance of fingers and toes. California and western medicine. (1932);xxxvii,6;388.

21. Girtler R; Fertschak W; Schwägerl W; Singh S K; et al. Hallux valgus 3.Journal of bone and joint surgery(2004)86,ProQuest Medical Library, 327

22. Ayub A,YaleS H, Bibbo C, Common Foot Disorders. Clinical M edicine \& Research (2005)3(2): 116-119.

23. Robinson A H N; Limbers J P. Modern concepts in the treatment of hallux valgus J ournal of Bone and Joint Surgery (2005) 87, 8; ProQuest Medical Library, 1038

24. Rossi N; Bartolozzi P. Percutaneous distal metatarsal osteotomy for correction of hallux valgus.J ournal of Bone and Joint Surgery (2005) 87, 6; ProQuest Medical Library.1191.

25. Stephens M M., Does shortening of the first ray in the treatment of adolescent hallux valgus. Journal of Bone and Joint Surgery(2006) 88 , 7: ProQuest M edical Library,858.

26. Kato T, Watanabe $S$. The etiology of hallux valgus in Japan. Clin Orthop (1981)157:7881.10.

27. Gilheany $M F$, Landorf $K B$, Robinson $P$. Hallux valgus and hallux rigidus: a comparison of impact on health-related quality of life in patients presenting to foot surgeons in Australia. Journal of Foot and Ankle Research (2008) 1:14

28. Inçel NA, Genc H, Yorgancioglu ZR, Erdem HR. Relation between hallux valgus deformity and lumbar and lower extremity biomechanics. KaohsiungJ M ed Sci. (2002)18(7):329-33.

29. Havlícek V, Kovanda M, Kunovský R. Surgical management of hallux valgus by techniques preserving the first metatarsophalangeal joint: long-term results. Acta Chir Orthop Traumatol Cech. (2007)74(2):10510.

30. Kayali C, Ozturk H, Agus H, Altay T, Hancerli O.The effectiveness of distal soft tissue procedures in hallux valgus. : J Orthop Traumatol. (2008)9(3):117-21. Epub 2008 Jul 22.

31. Christensen JC, Jennings M M. Normal and abnormal function of the first ray.Clin Podiatr M ed Surg. (2009)26(3):355-71

32. Foster J C. Congenital Over-riding of the Little Toe. Correspondence Bmj (1962) 990

33. Hambly E .Congenital Over-riding of the Little Toe. correspondence Bmj(1962)800. 
34. Ishii T, Miyagawa S, Fukubayashi T, Hayashi K. Subtalar stress radiography using forced dorsiflexion and supination. J Bone Joint Surg Br.(1996) 78:56

35. Andersen KP, Wethelund JO, Helming P, Søballe K. The stabilizing effect of the ligamentous structures in the sinus and canalis tarsi on movements in the hindfoot: an experimental study. Am J Sports M ed. (1988) 16:512-516.

36. Yamamoto H, Yagishito K, Ogiuchi T, Sakai H, Shinomiya K, M uneta T. Subtalar instability following lateral ligament injuries of the ankle. Injury.(1998) 29:265-268.

37. Hertel J, Denegar CR, Monroe MM, Stokes WL. Talocrural and subtalarjoint instability after lateral ankle sprain. M ed Sci Sports Exerc. (1999)31:1501-1508.

38. Van Bergeyk AB, Younger A, Carson B. CT analysis of hindfoot alignment in chronic lateral ankle instability. Foot Ankle Int. (2002)23:37-42. 